\title{
Cross-reaction of immune sera from patients with rickettsial diseases
}

\author{
K.E. HECHEMY, D. RAOULT*, J.FOX, Y. HAN, L. B. ELLIOTTt and J. RAWLINGSt \\ Wadsworth Center for Laboratories and Research, New York State Department of Health, Box 509, Albany, NY \\ 12201-0509, USA, 'C.H.U. La Timone, Marseille, France, and †Texas Department of Health, Austin, Texas, \\ USA
}

\begin{abstract}
Summary. Rickettsia rickettsii and Rickettsia conorii are the causative agents of two common and serious diseases, Rocky Mountain spotted fever and Mediterranean spotted fever, respectively. In patients naturally infected with either of these organisms, antibodies are produced which cross-react with antigens of the other so extensively that diagnostic tests usually cannot identify the causative agents. The results of this study indicate that serodiagnostic tests with antigen from one of these two organisms could be used to detect antibodies in patients with either of the two rickettsial diseases.
\end{abstract}

\section{Introduction}

Cross-reactions among rickettsiae of the spotted fever group have been known for many years. Rickettsia conorii, the causative agent of Mediterranean spotted fever, when injected into guineapigs, protects the animals against challenge with Rickettsia rickettsii (Badger, 1933; Walker et al., 1984). Plotz et al. (1944) subsequently showed that convalescent guinea-pig sera cross-reacted with antigen obtained from patients with Mediterranean spotted fever and Rocky Mountain spotted fever. The homologous titres with either antigen were significantly higher than the heterologous titres. Feng and Waner (1980) demonstrated that guineapigs immunised with $R$. montana produced antibodies that cross-reacted with $R$. rickettsii antigens and that protected the animal from fatal infection with $R$. rickettsii. In contrast, Pickens et al. (1965) and Lackman et al. (1965) demonstrated species specific-antibodies in mice. Philip et al. (1978) also showed little cross-reaction in microimmunofluorescence (micro-IF) tests when antisera from mice inoculated with $R$. rickettsii were tested against $R$. conorii, or when antisera from mice inoculated with $R$. conorii were tested against $R$. rickettsii.

Although the cross-reactivity of antibodies to rickettsiae of the spotted fever group in human sera is extensive, few reports have been published. Plotz et al. (1944) showed cross-reaction with $R$. conorii and $R$. rickettsii antigens in complement-fixation

Received 19 Sep. 1988; revised version accepted 16 Jan. 1989. tests of sera from 15 patients, ten of whom had Rocky Mountain spotted fever and five Mediterranean spotted fever. Philip et al. (1976) showed by immunofluorescence that sera from seven patients with Rocky Mountain spotted fever cross-reacted with $R$. conorii. The heterologous titres in both the complement fixation and immunofluorescence tests were significantly lower than the homologous titres.

In an evaluation of the specificity of a newly developed latex test for the detection of antibodies to $R$. conorii in patients with Mediterranean spotted fever (Hechemy et al., 1986), we also observed extensive cross-reaction with $R$. rickettsii expressed qualitatively as percentage of reactive sera. The heterologous antibody titres were mostly similar to those obtained in the homologous reaction.

We now describe our observations on the crossreactions of human sera from patients with Mediterranean spotted fever, Rocky Mountain spotted fever, or murine typhus, with the heterologous rickettsial antigens by use of three common serodiagnostic tests.

\section{Materials and methods}

\section{Antigens}

$R$. conorii (Moroccan strain) and $R$. rickettsii (Sheila Smith) were grown in Vero cells, purified as described by Weiss et al. (1975) and lyophilised. R. typhi (Wilmington) was a gift from Dr T. Tzianabos, Centers for Disease Control, Atlanta, GA, USA. Erythrocyte-sensitising 
substance from each organism was prepared as described by Anacker et al. (1975).

\section{Sera}

Sera of patients with Mediterranean spotted fever (56) were selected from positive samples submitted to the Marseille laboratory. Sera of patients with Rocky Mountain spotted fever (11) or murine typhus (12) were obtained from samples submitted to the Texas laboratory.

\section{Serological tests}

The serological reagents were prepared, and the tests performed, as described by Philip et al. (1976) (MicroIF), Anacker et al. (1975) (indirect haemagglutination test; IHA), and Hechemy et al. (1986) (latex test). The optimum concentrations of the erythrocyte-sensitising substances from the three antigen preparations used in the IHA and latex tests were determined by chessboard titration. This was done with a human serum pool reactive to each of the three rickettsial antigens in micro-IF tests. The micro-IF/Ig refers to the micro-IF test in which fluorescein isothiocyanate conjugate-specific goat antibody to human $\operatorname{IgA}+\operatorname{IgG}+\operatorname{IgM}$ (heavy + light chains) was used; micro-IF/IgG refers to goat antibody to human IgG ( $\gamma$ chain); micro-IF/IgM indicates goat antibody to human $\operatorname{IgM}(\mu$ chain). The minimum significant levels of reactivity (Philip et al., 1976; Hechemy et al., 1986) for each test were previously determined. The minimum significant levels of reactivity for the micro-IF tests with the fluorescein isothiocyanate conjugate specific for $\operatorname{IgA}+\operatorname{IgG}+\operatorname{IgM}, \operatorname{IgG}$ and IgM were titres of 128,128 and 32 respectively. For the indirect haemagglutination and latex tests, the minimum titres were 128 and 64 respectively.

\section{Statistical analysis}

Fisher's exact test was used to compare sera reactive with presumed "homologous" and presumed "heterologous" antigens.

\section{Results}

The qualitative test results (table I) indicated extensive cross-reaction among antigens of rickettsiae of the spotted fever group by all three tests. Cross-reaction of sera was less extensive with murine typhus group antigen than with the other antigens, especially in sera from patients with Rocky Mountain spotted fever.

Sera from patients with murine typhus crossreacted more with $R$. conorii than with $R$. rickettsii antigens, although the sample size was too small to assess statistical significance. Those sera also appeared to exhibit cross-reactions relatively more in micro-IF/IgM, latex, and IHA tests than in the micro-IF/IgG test.

Titration of sera from patients with Mediterranean spotted fever with rickettsial antigens showed that the titres (table II) were within one twofold dilution for $88 \%$ of the 56 sera tested by micro-IF/ Ig and micro-IF/IgG and for $60 \%$ tested by microIF/IgM, IHA and latex. For 12 of the sera higher titres were obtained with the heterologous $R$. rickettsii antigens by the IHA tests. With the 11 sera from patients with Rocky Mountain spotted fever, the titres with the heterologous $R$. conorii antigen were within one two-fold dilution for 10 , 10 , eight and 11 sera in the micro-IF/Ig, micro-IF/

Table I. Qualitative cross-reactivity of reactive sera with heterologous antigens in three tests

\begin{tabular}{|c|c|c|c|c|c|c|c|}
\hline \multirow[b]{3}{*}{ Diagnosis } & \multirow{3}{*}{$\begin{array}{l}\text { Heterologous } \\
\text { antigen }\end{array}$} & \multirow{3}{*}{$\begin{array}{l}\text { Homologous } \\
\text { antigen }\end{array}$} & \multicolumn{5}{|c|}{$\begin{array}{c}\text { Number of sera reactive with heterologous/ } \\
\text { homologous antigen in }\end{array}$} \\
\hline & & & \multicolumn{3}{|c|}{ Micro-IF } & \multirow[b]{2}{*}{ Latex test } & \multirow[b]{2}{*}{ IHA } \\
\hline & & & Ig & IgG & IgM & & \\
\hline $\begin{array}{l}\text { Mediterranean } \\
\text { spotted fever } \\
(n=56)\end{array}$ & $\begin{array}{l}\text { R. rickettsii } \\
\text { R. typhi }\end{array}$ & $\begin{array}{l}\text { R. conorii } \\
R . \text { conorii }\end{array}$ & $\begin{array}{r}52 / 56 \\
6 / 56\end{array}$ & $\begin{array}{r}44 / 47 \\
3 / 47\end{array}$ & $\begin{array}{r}34 / 49 \\
4 / 49\end{array}$ & $\begin{array}{l}48 / 56 \\
11 / 56\end{array}$ & $\begin{array}{r}55 / 56 \\
7 / 56\end{array}$ \\
\hline $\begin{array}{l}\text { Rocky Mountain } \\
\text { spotted fever } \\
(n=11)\end{array}$ & $\begin{array}{l}\text { R. conorii } \\
\text { R. typhi }\end{array}$ & $\begin{array}{l}R . \text { rickettsii } \\
\text { R. rickettsii }\end{array}$ & $\begin{array}{l}8 / 11 \\
0 / 8+\end{array}$ & $\begin{array}{l}7 / 7 \\
0 / 7\end{array}$ & $\left.\begin{array}{l}6 / 7 \\
3 / 6+\end{array}\right]^{*}$ & $\begin{array}{r}11 / 11 \\
2 / 11\end{array}$ & $\begin{array}{r}11 / 11 \\
1 / 11\end{array}$ \\
\hline $\begin{array}{l}\text { Murine typhus } \\
\quad(\mathrm{n}=13)\end{array}$ & $\begin{array}{l}\text { R. conorii } \\
R \text {. rickettsii }\end{array}$ & $\begin{array}{l}\text { R. typhi } \\
\text { R. typhi }\end{array}$ & $\left.\begin{array}{l}2 / 12 \\
0 / 12\end{array}\right]^{*}$ & $\left.\begin{array}{l}1 / 7 \\
0 / 7\end{array}\right]^{*}$ & $\left.\begin{array}{l}5 / 13 \\
2 / 13\end{array}\right]^{*}$ & $\begin{array}{l}8 / 13 \\
2 / 13\end{array}$ & $\left.\begin{array}{l}7 / 13 \\
8 / 13\end{array}\right]^{*}$ \\
\hline
\end{tabular}

Micro-IF = microimmunofluorescence test.

IHA = indirect haemagglutination test.

- Difference was not statistically significant ( $p>0.05$ ) (Fisher's exact test).

$\dagger$ Insufficient serum to complete all the micro-IF tests on all specimens. 
Table II. Quantitative cross-reactivity of 56 sera from patients with Mediterranean spotted fever sera with the heterologous $R$. rickettsii antigen

\begin{tabular}{l|ccc}
\hline & \multicolumn{3}{|c}{$\begin{array}{c}\text { Number of sera in which the heterolo- } \\
\text { gous: homologous titre ratio was }\end{array}$} \\
\cline { 2 - 3 } Test & $\leq 0 \cdot 25$ & $0 \cdot 5-2$ & $\geq 4$ \\
\hline Micro-IF & & & \\
Ig & 5 & 49 & 2 \\
IgG & 6 & 50 & 0 \\
IgM & 24 & 32 & 0 \\
IHA & 9 & 35 & 12 \\
Latex & 21 & 33 & 2 \\
\hline
\end{tabular}

Micro-IF $=$ microimmunofluorescence test $\quad \mathrm{IHA}=$ indirect haemagglutination test.

IgG, IgM and IHA tests respectively. In contrast, titres of only four sera were within one two-fold dilution in the latex test. For all sera in which crossreactions between spotted fever group and typhus group antigens were observed, the titres exhibited at least a four-fold difference. However, the sera from patients with murine typhus displayed relatively higher titres to $R$. conorii than to $R$. rickettsii.

\section{Discussion}

Rickettsial diseases, especially murine typhus, Mediterranean spotted fever and Rocky Mountain spotted fever continue to constitute an important public health problem in certain areas of the world. The production of tests for the serodiagnosis of each of the separate rickettsial diseases is not cost effective. This is because the number of patients is relatively small, the cost of preparation of the diagnostic reagents is high, and the antibiotic therapy is the same regardless of the specific rickettsial aetiology. Therefore, we investigated the cross-reactivity of sera from patients diagnosed as having rickettsial spotted fever or murine typhus in

\section{REFERENCES}

Anacker R L, Gerloff R K, Thomas L A, Mann R E, Bickel W D 1975 Immunological properties of Rickettsia rickettsii purified by zonal centrifugation. Infection and Immunity 11 : 1203-1209.

Badger L F 1933 Rocky Mountain spotted fever and Boutonneuse fever. Study of their immunological relationships. Public Health Report 48: 507-511.

Elisberg B L, Bozeman F M 1979 The rickettsiae. In: Lennette E H, Schmidt N J (eds) Diagnostic procedures for viral, rickettsial and chlamydial infections, 5th edn. American three tests which are currently the mainstay for the serodiagnosis of these diseases.

In the micro-IF test the whole organism is used to detect a range of rickettsial antigens. In contrast the latex and IHA tests make use of an $\mathrm{NaOH}$ solubilised extract of rickettsial organism composed mainly of carbohydrate or cabohydrate-containing fractions, and detect antibodies only to these fractions.

Cross-reactivity between the spotted fever group and the murine typhus group was not extensive and even when cross-reaction occurred, the differences in titre were large enough to differentiate between infection with the two rickettsial groups.

In contrast, extensive cross-reactions were observed within the spotted fever group, both qualitatively (number of sera) and quantitatively (titres). Considered quantitatively, the micro-IF/Ig and micro-IF/IgG tests, were relatively "less specific" than the other tests for the differentiation of Rocky Mountain spotted fever from Mediterranean spotted fever. This was not unexpected. The whole array of proteins and polysaccharide antigens on the organism is available to react with the antisera in the micro-IF test, whereas the protein components are excluded from the latex and IHA tests because of the $\mathrm{NaOH}$ treatment.

Because of the similarity of homologous and heterologous titres, infection with $R$. rickettsii and $R$. conorii organism cannot usually be differentiated by the standard diagnostic technique (Elisberg and Bozeman, 1979) unless the geographical origin of the infection is known. Thus 12 cases of Mediterranean spotted fever would have been diagnosed as Rocky Mountain spotted fever if sera had been submitted in the USA and tested by the IHA test. Conversely, the micro-IF/Ig, micro-IF/IgG or the IHA tests with either $R$. rickettsii or $R$. conorii antigens could be used for the serodiagnosis of either disease.

We thank Dr R. L. Anacker for critically reviewing this manuscript.

Public Health Association, Washington, DC, pp 10611108.

Feng W C, Waner J L 1980 Serological cross-reaction and crossprotection in guinea pig infected with Rickettsia rickettsii and Rickettsia montana. Infection and Immunity 28: 627629.

Hechemy K E, Raoult D, Eisemann C, Han Y S, Fox J A 1986 Detection of antibodies to Rickettsia conorii with a latex agglutination test in patients with Mediterranean spotted fever. Journal of Infectious Diseases 153; 132-135.

Lackman D B, Bell E J, Stoenner H G, Pickens E G 1965 The 
Rocky Mountain spotted fever group of rickettsias. Health Laboratory Science 2: 135-141.

Philip R N, Casper E A, Ormsbee R A, Peacock M G, Burgdorfer W 1976 Microimmunofluorescence test for the serological study of Rocky Mountain spotted fever and typhus. Journal of Clinical Microbiology 3: 51-61.

Philip R N, Casper E A, Burgdorfer W, Gerloff R K, Hughes L E, Bell E J 1978 Serologic typing of rickettsiae of the spotted fever group by microimmunofluorescence. Journal of Immunology 121: 1961-1968.

Pickens E G, Bell E J, Lackman D B, Burgdorfer W 1965 Use of mouse serum in identification and serologic classification of Rickettsia akari and Rickettsia australis. Journal of Immunology 94: 883-889.

Plotz H, Reagan R L, Wertman K 1944 Differentiation between fievre boutonneuse and Rocky Mountain spotted fever by means of complement fixation. Proceedings of the Society for Experimental Biology and Medicine 55: 173-176.

Walker D H, Montenegro M, Hegarty B C, Tringali G R 1984 Rocky Mountain spotted fever vaccine. A regional need. Southern Medical Journal 77: 447-449.

Weiss E, Coolbaugh J C, Williams J C 1975 Separation of viable Rickettsia typhi from yolk sac and L cell host components by renografin density gradient centrifugation. Applied Microbiology 30: 456-463. 